\title{
Research on Influence of Exhaust Characteristics and Control Strategy to DOC-Assisted Active Regeneration of DPF
}

\author{
Guanlin Liu ${ }^{1,2}$, Weiqiang Liu ${ }^{2, *}$, Yibin $\mathrm{He}^{1}$, Jinke Gong ${ }^{2}$ and Qiong $\mathrm{Li}^{1}$ \\ 1 College of Automotive Engineering, Hunan Industry Polytechnic, Changsha 410012, China; \\ gua@hnu.edu.cn (G.L.); heyibin2021@yeah.net (Y.H.); yifeng8457@163.com (Q.L.) \\ 2 State Key Laboratory of Advanced Design and Manufacturing for Vehicle Body, Hunan University, \\ Changsha 410082, China; gongjinke@hnu.edu.cn \\ * Correspondence: liuweiqiang@hnu.edu.cn
}

Citation: Liu, G.; Liu, W.; He, Y.; Gong, J.; Li, Q. Research on Influence of Exhaust Characteristics and Control Strategy to DOC-Assisted Active Regeneration of DPF. Processes 2021, 9, 1403. https://doi.org/ $10.3390 /$ pr9081403

Academic Editor: Alessandro D' Adamo

Received: 2 July 2021

Accepted: 10 August 2021

Published: 13 August 2021

Publisher's Note: MDPI stays neutral with regard to jurisdictional claims in published maps and institutional affiliations.

Copyright: (c) 2021 by the authors. Licensee MDPI, Basel, Switzerland. This article is an open access article distributed under the terms and conditions of the Creative Commons Attribution (CC BY) license (https:/ / creativecommons.org/licenses/by/ $4.0 /)$.

\begin{abstract}
For the purpose of designing a reasonable control strategy for DOC-assisted DPF regeneration, a mathematical model that describes the thermal phenomenon both in a diesel oxidation catalyst (DOC) and diesel particulate filter (DPF) during regeneration is developed. All boundary conditions of this model are obtained by experiments. The effects of the main exhaust parameters such as exhaust mass flow rate, exhaust temperature, oxygen concentration and emission of reactants are investigated comprehensively. The effects of two main parameters of control strategy, DOC-out temperature and soot loading, are analyzed as well. To quantify the effects of relevant parameters, the fuzzy grey relational analysis method is utilized to evaluate the correlation coefficient of all factors to key indexes of DPF regeneration such as maximum temperature, maximum rate of temperature increase and regeneration duration. The results of this work will greatly reduce the complexity of analysis and enable more rational control strategy design of DOC-DPF regeneration systems.
\end{abstract}

Keywords: DOC-assisted DPF regeneration; mathematical model; exhaust parameters; control strategy; fuzzy grey relational analysis

\section{Introduction}

With more and more stringent emission regulations of vehicles, the particulate emissions of diesel engines has raised a huge challenge for engine manufacturers and automotive engineers [1,2]. Great efforts have been made in the field of improving engine structure and combustion mode, such as high-pressure common rail injection system [3,4], HCCI (Homogeneous Charge Compression Ignition) [5-7], etc. [8-10], to reduce particle emission. Among all the technologies, the diesel particulate filter (DPF) is acknowledged to be the most effective device to reduce particulate emission [11,12]. Further, regeneration [13,14] is the key technique that determines the application and promotion of DPF.

Various regeneration methods have been implemented, such as post injection, microwave heating and continuous regeneration technology [15]. However, post injection in the cylinder causes engine performance deterioration and lubrication oil dilution [16]. Microwave heating is superior for its instantaneous penetration and selective absorption. Nevertheless, it is restricted by vehicle power supply and the complexity added to the electric control unit (ECU) [17]. Continuous regeneration technology (CRT) enables soot combustion at a relatively lower temperature, typically $250^{\circ} \mathrm{C}$. However, the catalyst used in a CRT system loses efficacy easily due to the high sulfur content in diesel oil, a process named catalyst poisoning [18]. At present, thermal regeneration of DPF assisted by a diesel oxidation catalyst (DOC) is widely used for its simplicity and reliability [19]. The working process of a DOC-DPF active regeneration system is shown in Figure 1. Firstly, after the regeneration is triggered, some amount of hydrocarbon (normally diesel fuel) is injected into the exhaust pipe, vaporizing and being oxidized in DOC along with those existing reactants in exhaust gas such as carbon monoxide, hydrocarbon and nitric oxides. Then, 
the outlet temperature of DOC rises to a pre-set target temperature (DOC-out temperature), which is normally $600{ }^{\circ} \mathrm{C}$. Finally, soot deposited in the DPF starts to burn until the regeneration is accomplished [20]. There are numerous investigations regarding DOC-DPF active regeneration. However, there are rarely studies concerning the influences of exhaust characteristics and control strategy parameters to regeneration.

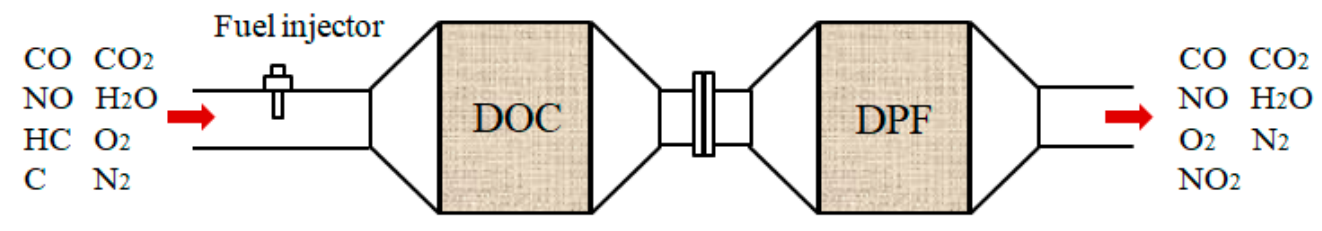

Figure 1. Working principle of a DOC-DPF system.

The majority of studies focus on the influence of geometrical parameters of DPF and fuel types on active regeneration. Koji Tsuneyoshi and Kazuhiro Yamamoto [21,22] compared the performance of square and hexagonal cells in terms of filtration, pressure drop and regeneration on test bench. Deng et al. [23] investigated the influence of diameter, length, wall thickness and cell diameter on continuous regeneration of DPF with the improved fuzzy grey relational analysis method and found the most relevant factor to properties in equilibrium state. José Rodríguez-Fernández et al. [24] investigated the effect of alternative fuels on soot reactivity and implications for DPF regeneration. These scholars left out the operational parameters (namely exhaust characteristics and control strategy parameters), which is a research gap that deserves special attention.

Additionally, many theoretical models of DOC-DPF have been built to analyze regeneration properties. Björn Lundberg [25] developed a kinetic and transport model of DOC to capture transient features for typical lean exhaust conditions. Chaitanya S. Sampara [26] determined global kinetics for the oxidation of diesel fuel, propylene, carbon monoxide, hydrogen and nitrogen monoxide. Tae Joong Wang and Seung Wook Baek [27] also estimated kinetic parameters of a diesel oxidation catalyst under actual vehicle operating conditions. Christopher Depcik and Dennis Assanis [28] built a one-dimensional model of DOC to illustrate the physical and chemical phenomena that exist in DOC. M. Schejbal et al. [29,30] developed a transient spatially 2D model to depict the combustion of soot by oxygen and nitrogen dioxide. Cozzolini [31] developed a DOC-DPF model to predict DPF loading and regeneration during engine transient cycles. To the best of our knowledge, very few of these models are used to analyze the effects of exhaust characteristics and control strategy parameters.

There are a few researches on regeneration strategy and control design of regeneration. Michelle Morcos [32] characterized ash deposition in DPF for the purpose of regeneration control. Carlo Beatrice et al. [33] explored the detailed characterization of particulate emissions of a catalyzed DPF using actual regeneration strategies. Ted N. Tadrous, Kevin Brown [34] and Qu Dawei et al. [35] developed both active and passive regeneration strategies of DPF for real-life optimization and retrofit. Bai Shuzhan et al. [36] investigated the influence of active control strategies on exhaust thermal management and Navtej Singh et al. [37] compared different DPF regeneration strategies using integrated system simulation. Jian Gong and Christopher J. Rutland [38] implemented pulsed injection of fuel in an exhaust pipe to optimize regeneration of DPF. Shuzhan Bai et al. [39] built a soot-loading estimation model to determine precisely the triggering of DPF regeneration. Jinbiao Ning and Fengjun Yan [40] developed a composite controller utilizing simulated and experimental data to modulate DOC-out temperature for DPF regeneration. Yong-Wha Kim and Michiel Van Nieuwstadt [41] and Olivier Lepreus [42] investigated model-based temperature control of DOC-out temperature to reject exhaust flow rate and temperature disturbances. Olivier Lepreux et al. [43] investigated the motion planning problem of DOC outlet temperature. In his paper, the trajectory of hydrocarbon injection was planned to 
follow a pre-defined profile of DOC outlet temperature. However, their work did not combine real exhaust conditions and remained at the theory stage.

In summary, the vast majority of research focuses on modeling of DPF regeneration and investigating its influencing factors mainly in regard to geometrical characteristics. Some preparatory investigations have been carried out in terms of DOC-out temperature control for DPF regeneration. However, exhaust characteristics and control parameters which have significant implications for DPF regeneration are rarely investigated by researchers. In this paper, the effects of main exhaust characteristics such as exhaust flow rate, oxygen concentration and emission of reactants, or control strategies such as DOC-out temperature and soot loading, have been investigated and their correlations with maximum temperature, maximum rate of temperature increase and regeneration duration of DPF have been evaluated utilizing the improved fuzzy grey relational analysis method. Based on the results of this work, a more reasonable control strategy and DOC-out temperature controller can be implemented which considers realistic exhaust conditions and DPF status.

\section{Mathematical Model and Chemical Mechanisms}

In this section, a mathematical model of diesel oxidation catalyst and diesel particulate filter comprising a series of partial differential equations will be proposed, along with mechanisms of chemical reactions during regeneration in both devices. The inlet boundary condition of DOC is measured on an engine test bench, including flow rate, exhaust temperature, oxygen concentration and composition of exhaust. The outlet boundary conditions of DOC, which are computed from the theoretical model, are treated as the inlet boundary condition of DPF. In this way, the whole process of computation is completed.

\subsection{Diesel Oxidation Catalyst Model}

For flow through reactors such as DOC, quasi-steady approximation is assumed due to the short residence time of gas in the reactor compared to other time scales of interest. This assumption simplified the substantial derivative and replaced them with a simpler spatial derivative. The flow is laminar, based on Reynolds number analysis. Density of gas is calculated by ideal gas law. Body forces such as gravity are neglected.

Continuity equation:

$$
\frac{\partial}{\partial z}\left(\rho_{g} v\right)=0
$$

Momentum equation:

$$
\varepsilon \frac{\partial p}{\partial z}+\varepsilon \rho_{g} v \frac{\partial v}{\partial z}=-S f \frac{1}{2} \rho_{g} v^{2}
$$

where $\varepsilon$ is the void fraction of DOC substrate, $S$ is surface area per DOC volume and $f$ is the friction factor.

Solid-phase energy equation:

$$
\psi_{s} \frac{\partial T_{s}}{\partial t}=\frac{\partial}{\partial z}\left(f_{s b} \lambda_{s b} \frac{\partial T_{s}}{\partial z}\right)+h S\left(T_{g}-T_{s}\right)-\sum_{j=1}^{n r c t} \Delta H_{j} r_{j}+\frac{P}{V}+h_{x} S_{x}\left(T_{x}-T_{s}\right)
$$

where $\Psi_{s}$ is the effective heat capacity of DOC, $f_{s b}$ is the solid fraction of DOC substrate and $\lambda_{s b}$ is the thermal conductivity of substrate. On the right-hand side of the equation, the five terms are, respectively, conduction, convection, reaction enthalpy, external input and heat exchange with ambient The heat transfer coefficient $h$ is related to a single Nusselt number for fully developed laminar flow as follows:

$$
h=N u \frac{\lambda_{g}}{D_{h}}
$$


Gas-phase energy equation:

$$
\varepsilon \rho_{g} v C_{p g} \frac{\partial T_{g}}{\partial z}=h S\left(T_{s}-T_{g}\right)
$$

Due to the relatively short dwell time of exhaust gas in DOC, all chemical reactions are considered as global reactions instead of surface reactions. In addition, the effects of adsorption and desorption are taken into account. The injected diesel fuel is treated as propylene for simplicity. The main chemical reactions inside DOC are described as follows:

$$
\begin{gathered}
\mathrm{CO}+1 / 2 \mathrm{O}_{2} \stackrel{k_{1}}{\rightarrow} \mathrm{CO}_{2} \\
\mathrm{HC}+5 / 4 \mathrm{O}_{2} \stackrel{k_{2}}{\rightarrow} \mathrm{CO}_{2}+1 / 2 \mathrm{H}_{2} \mathrm{O} \\
\mathrm{NO}+1 / 2 \mathrm{O}_{2} \stackrel{k_{3}}{\rightarrow} \mathrm{NO}_{2} \\
\mathrm{C}_{3} \mathrm{H}_{6}+9 / 2 \mathrm{O}_{2} \stackrel{k_{4}}{\rightarrow} 3 \mathrm{CO}_{2}+3 \mathrm{H}_{2} \mathrm{O} \\
\mathrm{C}_{3} \mathrm{H}_{6}+\mathrm{Z} \stackrel{k_{5}}{\rightleftarrows} \mathrm{Z}\left(\mathrm{C}_{3} \mathrm{H}_{6}\right)
\end{gathered}
$$

where $k_{i}$ is the reaction constant and $Z$ is the catalytic site of DOC. All the reaction rates are computed based on an Arrhenius-type function.

\subsection{Diesel Particulate Filter Model}

A single pair consisting of an inlet channel and outlet channel is shown in Figure 2. As depicted in Figure 2, exhaust with soot flows through the porous media of the filter wall and leave soot particles deposited as a soot cake on the surface of the channel. Figure 2 also shows the computation domain of the governing equations. Pre-mentioned model assumptions are also valid here.

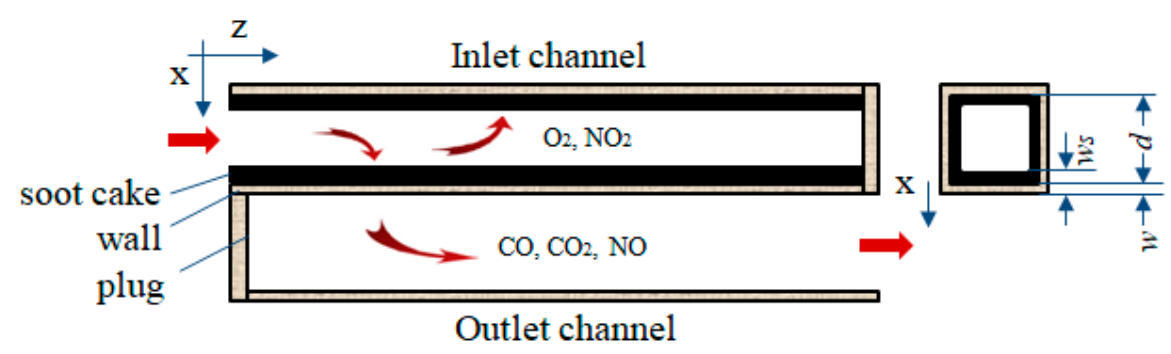

Figure 2. Schematic diagram of one pair of DPF channels.

The mass conservation equation of channel gas, momentum equation of channel gas and energy balance equation in the wall, which are derived from the model proposed by Bissett [44], are depicted as follows:

Conservation of mass equation of channel gas:

$$
\frac{\partial\left(\rho_{i} v_{i}\right)}{\partial z}=(-1)^{i}(4 / d) \rho_{w} v_{w}
$$

where value $i=1$ represents the inlet channel and $i=2$ represents the outlet channel.

Conservation of momentum of channel gas:

$$
\frac{\partial P_{i}}{\partial z}+\frac{\partial\left(\rho_{i} v_{i}^{2}\right)}{\partial z}=-a \mu T_{i} v_{i} / d^{2}
$$

where $a$ is the square channel pressure drop correlation and $\mu$ is exhaust viscosity. 
Conservation of enthalpy:

$$
\begin{aligned}
& \frac{\partial}{\partial t}\left(\rho_{p} w C_{p p}\left(T_{w}\right) T_{w}+\rho_{s} w_{s} C_{p s}\left(T_{w}\right) T_{w}\right)=-h_{1}\left(T_{w}-T_{1}\right)-h_{2}\left(T_{w}-T_{2}\right) \\
& +\phi(z, t)+\lambda_{p} \frac{\partial}{\partial z}\left(w \frac{\partial T_{w}}{\partial z}\right)+\lambda_{s} w_{s} \frac{\partial^{2} T_{w}}{\partial z^{2}}
\end{aligned}
$$

Normally, $90 \%$ of nitric oxides in engine exhaust are nitrogen monoxide. When the exhaust passes through the DOC, the nitrogen monoxide is oxidized into nitrogen dioxide. Therefore, the regeneration mechanism inside DPF consists of soot oxidation by both oxygen and nitrogen dioxide. The latter is called continuous regeneration. The detailed chemical reactions are depicted as follows:

$$
\begin{gathered}
\mathrm{C}+1 / 2 \mathrm{O}_{2} \stackrel{k_{6}}{\rightarrow} \mathrm{CO} \\
\mathrm{C}+\mathrm{O}_{2} \stackrel{k_{7}}{\rightarrow} \mathrm{CO}_{2} \\
\mathrm{C}+\mathrm{NO}_{2} \stackrel{k_{g}}{\rightarrow} \mathrm{CO}+\mathrm{NO} \\
\mathrm{C}+2 \mathrm{NO}_{2} \stackrel{k_{9}}{\rightarrow} \mathrm{CO}_{2}+2 \mathrm{NO} \\
\mathrm{C}+\mathrm{NO}_{2}+1 / 2 \mathrm{O}_{2} \stackrel{k_{10}}{\rightarrow} \mathrm{CO}_{2}+\mathrm{NO} \\
\mathrm{C}+\mathrm{NO}_{2}+1 / 2 \mathrm{O}_{2} \stackrel{k_{11}}{\rightarrow} \mathrm{CO}+\mathrm{NO}_{2}
\end{gathered}
$$

where $k_{i}$ is the reaction constant and all the reaction rates are also computed based on an Arrhenius-type function. All parameters of the Arrhenius formula including reactions both in DOC and DPF are cited from the AVL Boost theory manual [45]. Time step of solver is set as $0.1 \mathrm{~s}$. Spatial discretization is implemented by second-order upwind method. Time variable is discretized implicitly.

\section{Experimental Exhaust Characteristics and Emission Measurements}

The exhaust parameters including mass flow rate, temperature and composition of a specific diesel engine are measured on a test bench under different engine speeds and output powers. All the acquired data are treated as the inlet boundary condition of DOC. Then, the outlet boundary condition of DOC is computed using the above-mentioned theoretical model. Subsequently, the computed results are used as an inlet boundary condition of DPF to compute the key indexes concerned during regeneration.

For accuracy of exhaust characteristics measurements, the DOC and DPF devices are installed in the exhaust pipe during testing, since after-treatment devices alter the emission levels of the engine. The test bench includes a diesel engine, DOC-DPF, a positive displacement air flow meter (Romet G65) to measure intake air flow rate, a Horiba gas analyzer (MEXA-9100HEGR) to measure gaseous emissions, a differential mobility spectrometer (combustion DMS500) to measure particulate emission, a fuel consumption meter (MCS-960 gravimetric) to measure fuel consumption rate and a dynamometer (MS1713-4 electrical) to adjust the output power and speed of diesel engine. In Figure 3, the primary equipment is depicted. In the right part, a data acquisition and display module is shown.

The substrate of DOC is made of cordierite. All the thermal properties in computation are based on standard cordierite material. The wash-coat material is alumina and the detailed parameters of DOC are shown in Table 1. 


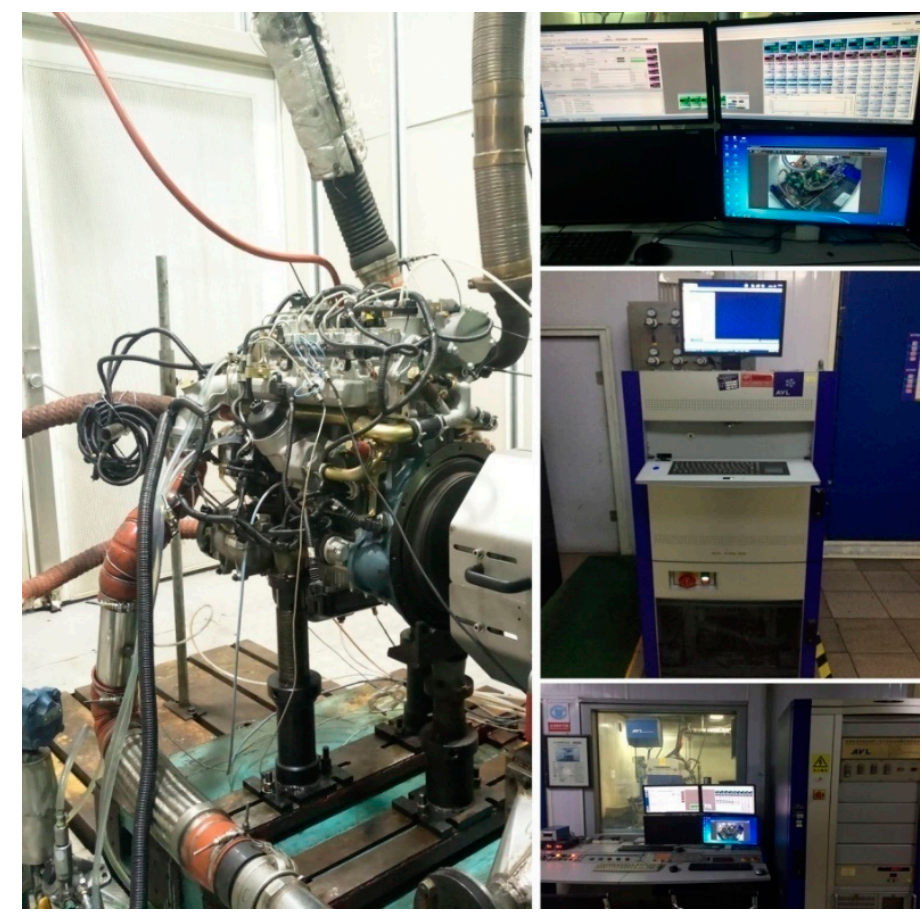

Figure 3. Main equipment of test bench.

Table 1. Parameters of DOC.

\begin{tabular}{cc}
\hline Parameters & Value \\
\hline Frontal area $\left(\mathrm{mm}^{2}\right)$ & 20,000 \\
Length $(\mathrm{mm})$ & 160 \\
Cell density $\left(1 / \mathrm{in}^{2}\right)$ & 400 \\
Wall thickness $(\mathrm{m})$ & $1.5 \times 10^{-4}$ \\
Wash-coat thickness $(\mathrm{m})$ & $3 \times 10^{-5}$ \\
Channel shape & Square \\
Substrate material & Cordierite \\
Wash-coat material & Alumina \\
\hline
\end{tabular}

The substrate of DPF is made of cordierite. Additionally, the thermal properties used in computation are based on standard cordierite material. No cerium catalyst or fuel additive is considered here. The main parameters of DPF are depicted in Table 2.

Table 2. Parameters of DPF.

\begin{tabular}{cc}
\hline Parameters & Value \\
\hline Frontal diameter $(\mathrm{mm})$ & 160 \\
Length $(\mathrm{mm})$ & 240 \\
Cell density $\left(1 / \mathrm{in}^{2}\right)$ & 100 \\
Wall thickness $(\mathrm{mm})$ & 0.4318 \\
Channel shape & Square \\
Substrate material & Cordierite \\
\hline
\end{tabular}

The DOC-DPF is equipped on a YC4G180-30 diesel engine which meets the national emission regulation III. The detailed parameters of the diesel engine are indicated in Table 3. 
Table 3. Parameters of diesel engine.

\begin{tabular}{cc}
\hline Parameters & Value \\
\hline Type & 4 -stroke \\
Cylinder no. & 4 \\
Stroke (mm) & 110 \\
Connecting rod (mm) & 152 \\
Compression ratio & 18 \\
Displacement (l) & 5.2 \\
Air aspiration & turbo-charged/inter-cooled \\
\hline
\end{tabular}

In order to investigate the effect of exhaust parameters on DOC-DPF regeneration, steady-state parameters of engine exhaust are in need. In this paper, the universal performance characteristics map of the YC4G180-30 engine is measured. The speed varies from 1000 to $3600 \mathrm{r} / \mathrm{min}$ with an increment of $200 \mathrm{r} / \mathrm{min}$ and the output power varies from 10 to $100 \mathrm{~kW}$ with an increment of $10 \mathrm{~kW}$. The acquired data utilized in this paper include intake flow rate, fuel consumption rate, temperature after turbocharger, oxygen concentration and emission of reactants such as carbon monoxide, hydrocarbon, nitrogen oxide and unburned fuel. The mass flow rate of exhaust is computed by adding intake mass flow rate and fuel consumption rate. All the measured data are treated as the inlet boundary condition of DOC to investigate the regeneration performance of DPF under different exhaust conditions and control strategies.

\section{Results and Discussion}

\subsection{Effects of Exhaust Flow Rate and Temperature to DOC-DPF Regeneration System}

Normally, the outlet temperature of DOC is kept constant or following a pre-defined trajectory. Therefore, exhaust flow rate and exhaust temperature synchronously determine the amount of propylene the injector has to inject. In addition, the mass flow rate of the exhaust can impact the regeneration process by altering heat transfer intensity between DPF substrate and exhaust, which will be discussed later.

Figure 4 shows the experimental data of exhaust temperature after turbocharger (left) and exhaust mass flow rate (right) under different engine speed and output power. The temperature of exhaust is measured after turbocharger, before DOC. The mass flow rate of exhaust is computed by adding the mass of intake air and consumed diesel fuel.
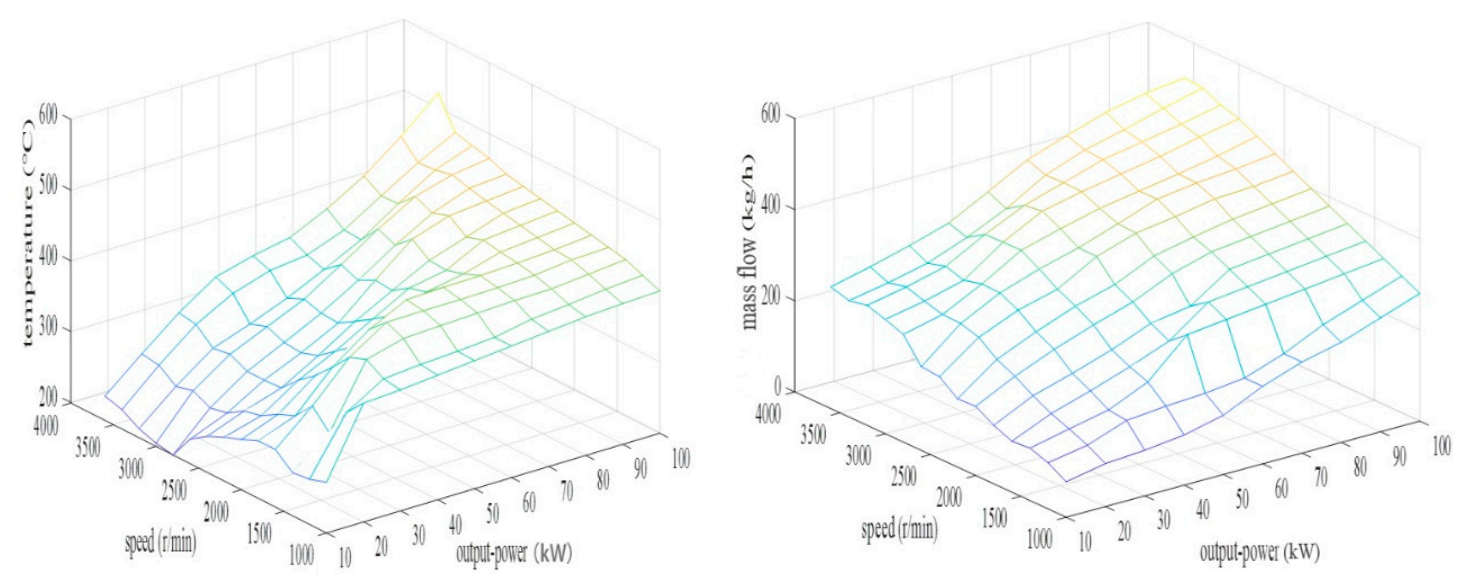

Figure 4. Exhaust temperature after turbocharger (left) and exhaust mass flow rate (right) under different speeds and output powers.

To treat the DOC as a zero-dimensional model, the amount of propylene needed to be injected in front of the DOC in order to reach the specific DOC-out temperature can be 
calculated by the energy conservation equation of a DOC under steady state. The formula of the energy conservation equation is as follows:

$$
\eta \dot{m} \Delta H=v \rho_{g} A_{0} C_{p g}\left(T_{\text {set }}-T_{\text {exg }}\right)
$$

where $\eta$ is the conversion rate of injected propylene, $\dot{m}$ is the mass flow rate of injected propylene, $\Delta H$ is low heating value of propylene, $A_{0}$ is the open frontal area of DOC and $T_{\text {set }}$ is the predefined DOC-out temperature which is normally the control target.

For the purpose of simplicity, the diesel fuel is treated as propylene and totally vaporized before DOC inlet. Another assumption is that the DOC is designed to enable chemical reactions and heat transfer with very high efficiency. Consequently, the conversion rate of propylene in DOC is regarded as $95 \%$ with high conversion rate and $90 \%$ with low conversion, according to engine working condition. Heat loss of the DOC to ambientwas neglected. The calculated mass flow of injected fuel was used as the input of the numerical model. The simulated DOC outlet temperature was very close to $T_{\text {set }}$. In Figure 5, the computed propylene mass flow based on Equation (20) is depicted.

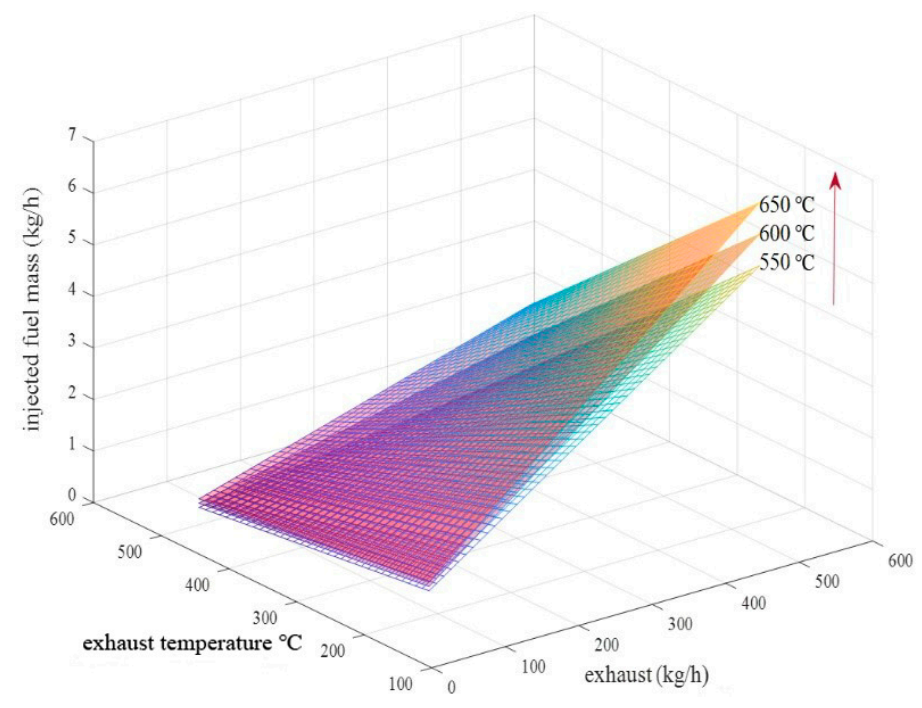

Figure 5. Injected fuel mass under different engine working conditions.

The range of exhaust temperatures of the tested engine is between 180 and $520^{\circ} \mathrm{C}$ and the exhaust flow rate ranges between 70 and $520 \mathrm{~kg} / \mathrm{h}$. Figure 5 indicates the general trend that the required amount of propylene increases with the increase in exhaust mass flow and decrease in temperature, and vice versa. Fuel was injected by an injector upstream of the DOC inlet to guarantee full vaporization and mixing. Injection was triggered when pressure drop along the DPF reached a specific value. With larger $T_{\text {set }}$, namely the targeted DOC-out temperature, the map of injected propylene mass rate shifts upwards, as the red arrow in Figure 5 shows. In practical application, the exhaust temperature and mass flow rate can be obtained by the interpolated map in Figure 4. Then, these obtained values can be utilized to obtain the amount of propylene by inquiring the interpolated map in Figure 5.

Normally, if the exhaust temperature is below the light-off temperature of DOC, the injected fuel will not react and further causes large hydrocarbon slip. Therefore, the fuel injection can only be triggered when the exhaust temperature is above this light-off temperature. In this paper, the minimum exhaust temperature of the tested engine is $187^{\circ} \mathrm{C}$, which is higher than the light-off temperature. Consequently, the light-off phenomenon of DOC will not be discussed in this paper, but must be considered in real control strategies.

To further investigate the effects of exhaust flow rate on the process of DPF regeneration, three cases are selected, which are 3600, 2000 and $1200 \mathrm{r} / \mathrm{min}$, and the output power is 60,50 and $30 \mathrm{~kW}$, respectively. These output powers are selected to keep the exhaust 
temperature consistent in each case, which is $380{ }^{\circ} \mathrm{C}$. By doing this, the exhaust flows into the DOC with the same state in three cases. The mass flow rate of the exhaust in each case is $428.8,286.91$ and $155.1 \mathrm{~kg} / \mathrm{h}$, respectively. The soot loading in the three cases is $6 \mathrm{~g} / \mathrm{L}$ and the DOC-out temperature is kept at $600{ }^{\circ} \mathrm{C}$.

Figure 6 depicts the numerical results of the temperature evolution of the DPF substrate at different exhaust flow rates at a normalized axial position of 0.9. It is worth noting that the temperature profile of the substrate can be regarded as a heat wave propagating from the front part of DPF to the rear part. The peak temperature of the wave rises along the axial direction. In addition, there is a higher amount of soot deposited in the rear part of the DPF channel, which causes a higher rising rate of temperature according to the research of K. Yamamoto et al. [46]. Consequently, the 0.9 normalized position is chosen to represent the maximum temperature and maximum rate of temperature increase inside DPF. In Figure 6, the dashed lines indicate the timing when the rate of temperature increase reaches the maximum. Under all engine speeds, the temperature of DPF rises rapidly to its peak value and then cools down to the temperature of the DPF inlet gas. It can be observed that both maximum temperature and rate of temperature increase decrease with the increase in engine speed. This can be explained by the fact that when the mass flow rate increases, the velocity in the channel increases correspondingly. Therefore, the convection and heat transfer between exhaust gas and substrate enhances and further removes more enthalpy generated by soot oxidation, while in low engine speed, the volumetric speed of the exhaust gas is lower, relatively, which makes the heat easy to accumulate in the DPF substrate. Therefore, both the maximum temperature and rate of temperature increase decrease with the increase in engine speed. Table 4 shows specific values of maximum temperature, rate of temperature increase and regeneration duration in each case.

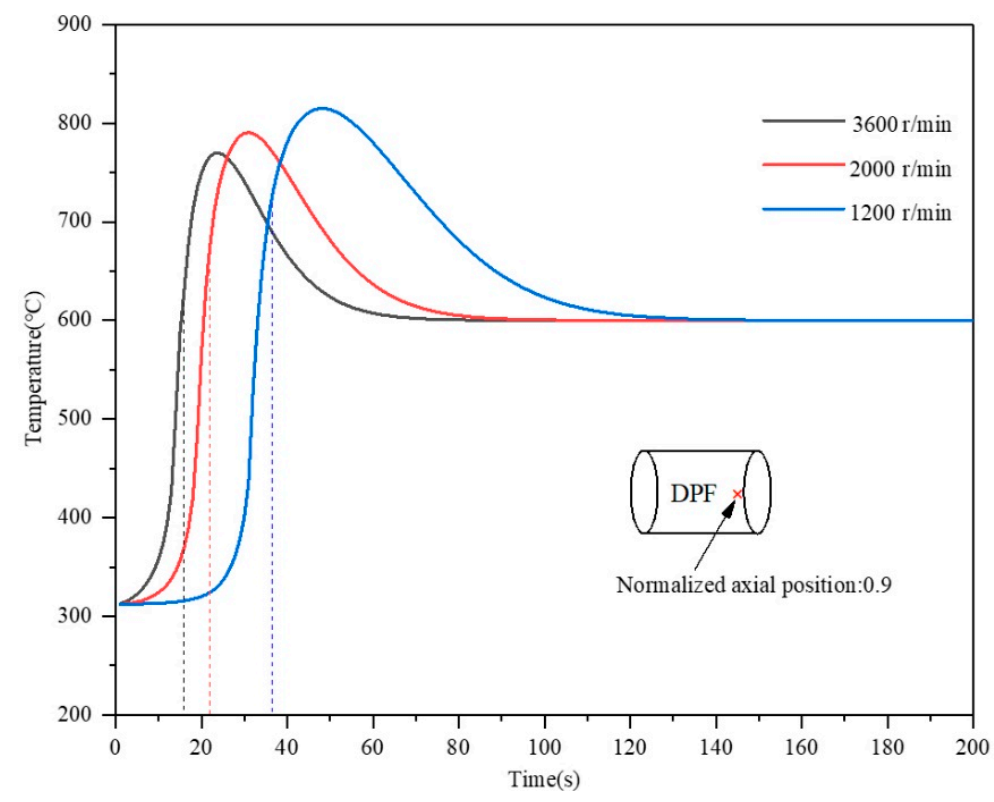

Figure 6. Substrate temperature of DPF at 0.9 normalized axial position under different exhaust mass flow rates.

Table 4. Regeneration characteristics under different engine speeds.

\begin{tabular}{ccccc}
\hline Engine Speed $(\mathbf{r} / \mathbf{m i n})$ & $\boldsymbol{T}_{\max }\left({ }^{\circ} \mathbf{C}\right)$ & $\dot{T}_{\max }\left({ }^{\circ} \mathbf{C} / \mathbf{s}\right)$ & $\boldsymbol{t}_{\text {reg }}(\mathbf{s})$ & $\dot{m}(\mathbf{k g} / \mathbf{h})$ \\
\hline 1200 & 814.8 & 89.8 & 50 & 0.81 \\
2000 & 790.4 & 84.1 & 38 & 1.61 \\
3600 & 769.6 & 82.9 & 32 & 2.23 \\
\hline
\end{tabular}


The data in Table 4 further explain the profiles of Figure 6. The third column in Table 4 shows that the duration of regeneration decreases with engine speed. This is due to the large oxygen mass that promotes the oxidation speed of soot under a higher engine speed. However, the oxygen concentrations in all cases are abundant enough to oxidize soot normally. The fourth column shows injection rate of propylene in order to reach $600{ }^{\circ} \mathrm{C}$ DOC outlet temperature.

\subsection{Effects of DPF Soot Loading and DOC-Out Temperature on DPF Regeneration}

In real application, mass of soot loading in DPF and DOC-out temperature are two of the most significant parameters in designing reasonable control strategies. In this chapter, the parameters in Table 4, such as maximum temperature, maximum rate of temperature increase and regeneration duration are investigated under different soot loading and DOC-out temperature. The results can instruct the design of rational control strategies.

The cruising speed of the engine, which is $2000 \mathrm{r} / \mathrm{min}$, is chosen in computation. The other speeds have similar patterns. The tested mole fraction of oxygen is $10 \%$. The mass of soot loading varies between 3,6 and $9 \mathrm{~g} / \mathrm{L}$, respectively. The DOC-out temperature varies between 550, 600 and $650{ }^{\circ} \mathrm{C}$, respectively. These values are frequently met in running vehicles. Figure 7 shows the temperature evolution under different soot mass loadings and DOC-out temperatures.

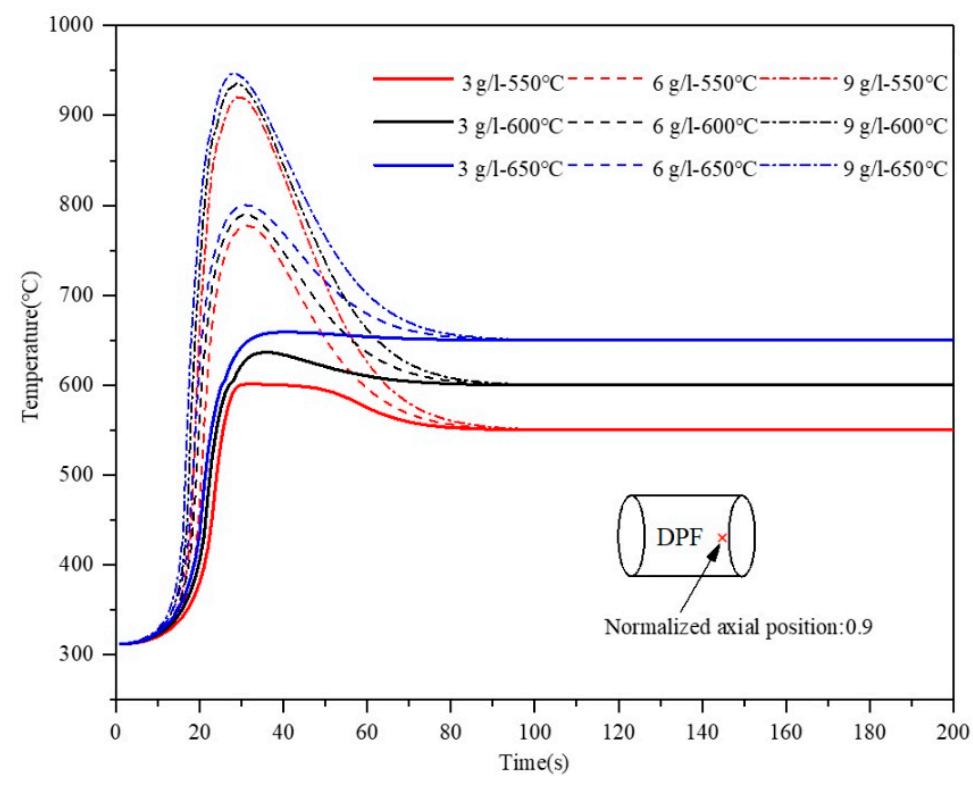

Figure 7. Substrate temperature of DPF at 0.9 normalized axial position under different soot loadings and DOC-out temperatures.

From Figure 7, the temperature rises rapidly to peak temperature and cools down to the temperature of DOC-out temperature, except for $3 \mathrm{~g} / \mathrm{L}$ of soot loading. The maximum temperature increases with the increase in soot loading and DOC-out temperature. However, the influence of soot loading is more obvious. Figure 7 indicates that when the soot loading is constant and DOC-outlet temperature varies from 550 to $650{ }^{\circ} \mathrm{C}$, the curves of temperature evolution are very similar to each other. When the DOC-outlet temperature is constant and soot loading varies from 3 to $9 \mathrm{~g} / \mathrm{L}$, the differences are very obvious. In addition, when soot loading is relatively low $(3 \mathrm{~g} / \mathrm{L})$, as the solid lines in Figure 7 show, temperature rise compared to DOC-out temperature due to soot oxidation is very inconspicuous. In the case where soot loading is $3 \mathrm{~g} / \mathrm{L}$ and DOC-out temperature is $650{ }^{\circ} \mathrm{C}$, the maximum temperature of the DPF substrate is almost equal to the exhaust temperature of the DOC outlet. From the above analysis, we can conclude that soot loading is the more significant factor influencing the maximum temperature of DPF regeneration, and the specific data regarding key indexes of regeneration are depicted in Figure 8. 


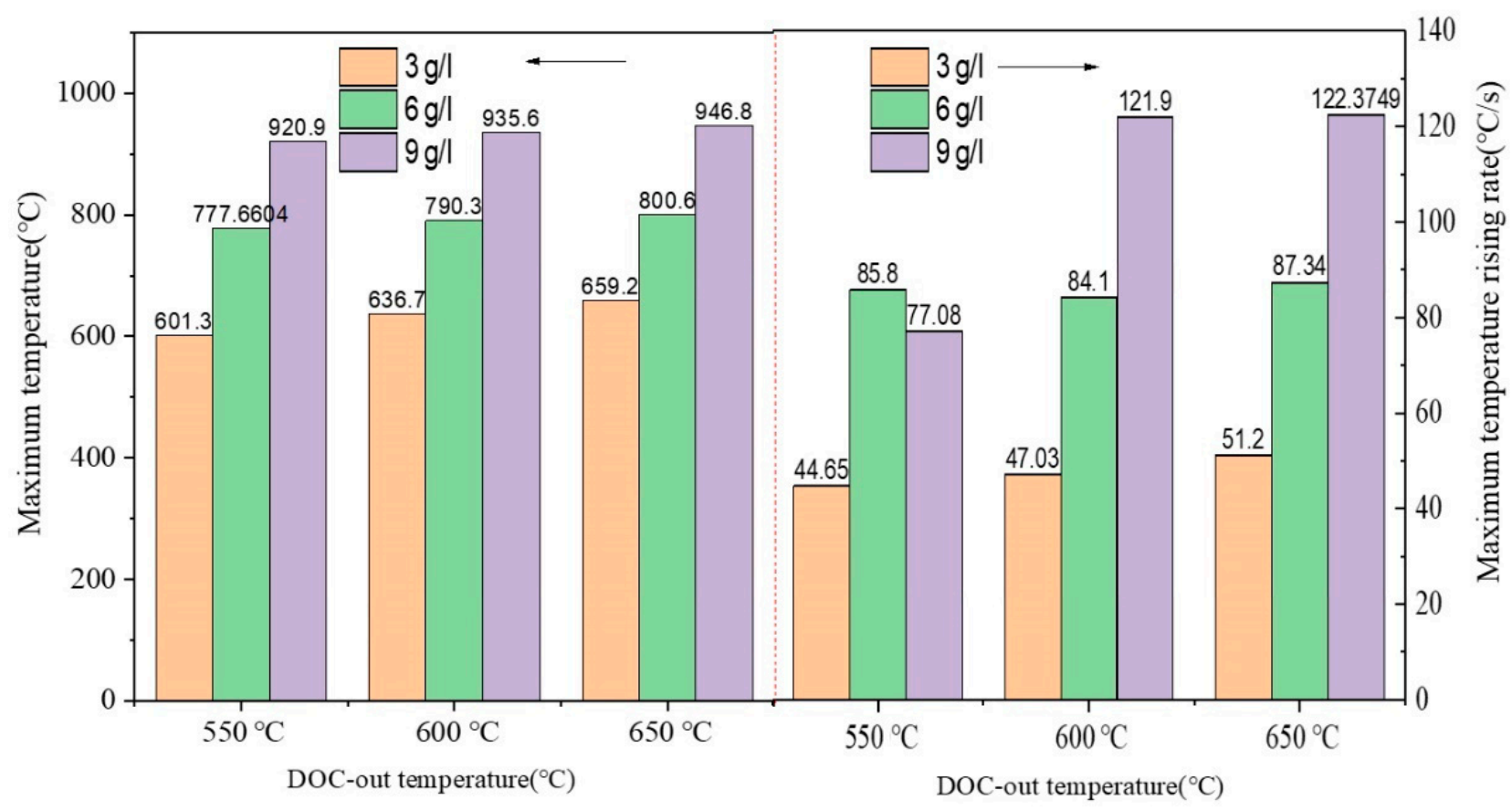

Figure 8. Maximum temperature under different DOC-out temperatures and soot loadings (left). Maximum rate of temperature increase under different DOC-out temperature and soot loading (right).

Figure 8 indicates that the maximum temperature of DPF substrate increases with both DOC-out temperature and soot loading, and the latter takes a much more obvious effect. The maximum rate of temperature increase has a similar trend, except for the low DOC-out temperature scenario. In this scenario, the maximum rate of temperature increase decreases when the soot loading increases from 6 to $9 \mathrm{~g} / \mathrm{L}$. This can be explained by the fact that when soot loading is as high as $9 \mathrm{~g} / \mathrm{L}$, DOC-out temperature becomes a limiting factor in the soot oxidation. This gives engineers a hint that when soot loading is high, DOC-out temperature can be decreased to restrict the maximum rate of temperature increase in DPF.

Figure 9 shows the duration of regeneration in each case. The red dashed line shows the injection rate of propylene in each case. The duration increases with soot loading in medium DOC-out temperature, namely $600{ }^{\circ} \mathrm{C}$. The duration decreases dramatically and then increases slightly with the increase in soot loading when the DOC-out temperature is $550{ }^{\circ} \mathrm{C}$. This can be explained by the fact that when the temperature and soot loading are both low, the soot oxidation is slow due to the very sparse distribution of soot in the DPF substrate and the low temperature. The duration increases and then decreases slightly with the increase in soot loading when the DOC-out temperature is $650{ }^{\circ} \mathrm{C}$. This indicates that when the DOC-out temperature is as high as $650^{\circ} \mathrm{C}$, concentration of soot in DPF is the limiting factor of oxidation speed. However, the duration of regeneration does not vary much except for the first case. This gives the impression that when the soot loading is low, it is not cost-effective to start regeneration if the DOC-out temperature is low. 


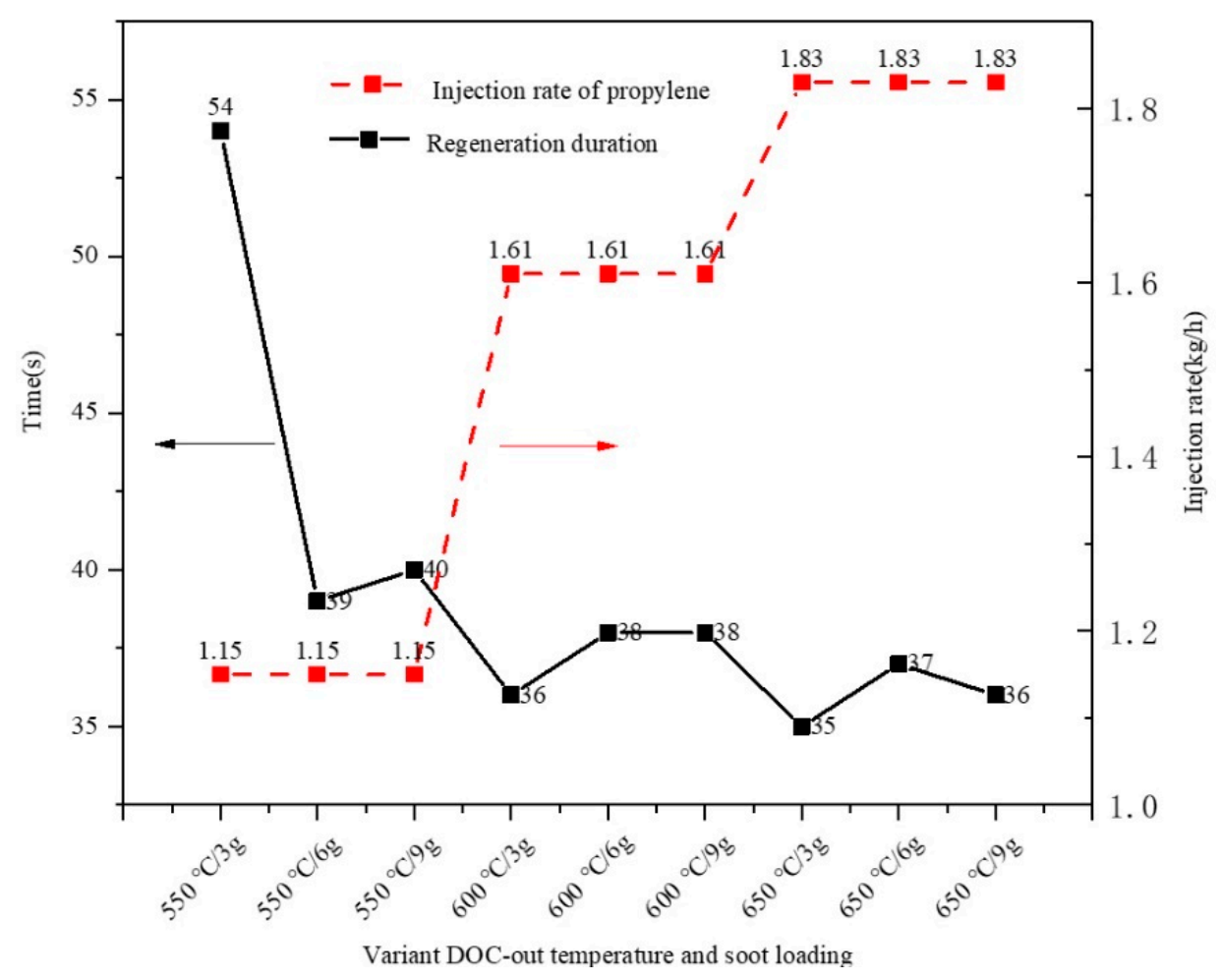

Figure 9. Regeneration duration under varying DOC-out temperatures, soot loadings and propylene injection rates.

\subsection{Effects of Oxygen Concentration and Reactants Emission in Exhaust}

Normally, the mole concentration of oxygen in diesel exhaust gas varies from $5 \%$ to $15 \%$ according to different working conditions. In the previous analysis, the oxygen concentration is $10 \%$ and regeneration can conduct smoothly under this oxygen concentration. In this section, $15 \%, 10 \%, 5 \%$ and $3 \%$ oxygen concentration are selected to investigate the regeneration of DPF. The 2000 speed and $50 \mathrm{~kW}$ operating point of engine are chosen. The soot loading is $6 \mathrm{~g} / \mathrm{L}$ and DOC-out temperature is kept at $600^{\circ} \mathrm{C}$.

Figure 10 depicts the temperature evolution of DPF substrate at an axial position of 0.9. The four curves in Figure 10 almost overlap, which indicate that the mass flow rate of oxygen is abundant enough under all oxygen concentrations, while the data in Table 4 show that when engine speed is as low as idle speed, the regeneration will last long, which reveals that mass flow of oxygen might not be adequate enough in this situation. Therefore, air auxiliary devices should be applied when engine speed is very low. It is also worth noting from the partially enlarged picture in Figure 10 that the soot oxidation is faster with the increase in oxygen concentration, which is reasonable because of the increase in reactant concentration. However, the maximum temperature is lower with the increase in oxygen concentration. This phenomenon can be explained by this: when the oxygen concentration is decreasing, the other compositions in exhaust gas, whose molar masses are larger than oxygen, such as nitrogen, carbon monoxide and hydrocarbon, are increasing. Therefore, the density of exhaust gas is increasing, which makes the volume flow rate of exhaust decrease under constant mass flow rate. Further, the convection between exhaust and substrate weakens. Ultimately, the maximum temperature of the substrate is higher with the decrease in oxygen concentration. In general, the oxygen is abundant enough under the majority of the operating points of the engine to support soot oxidation. 


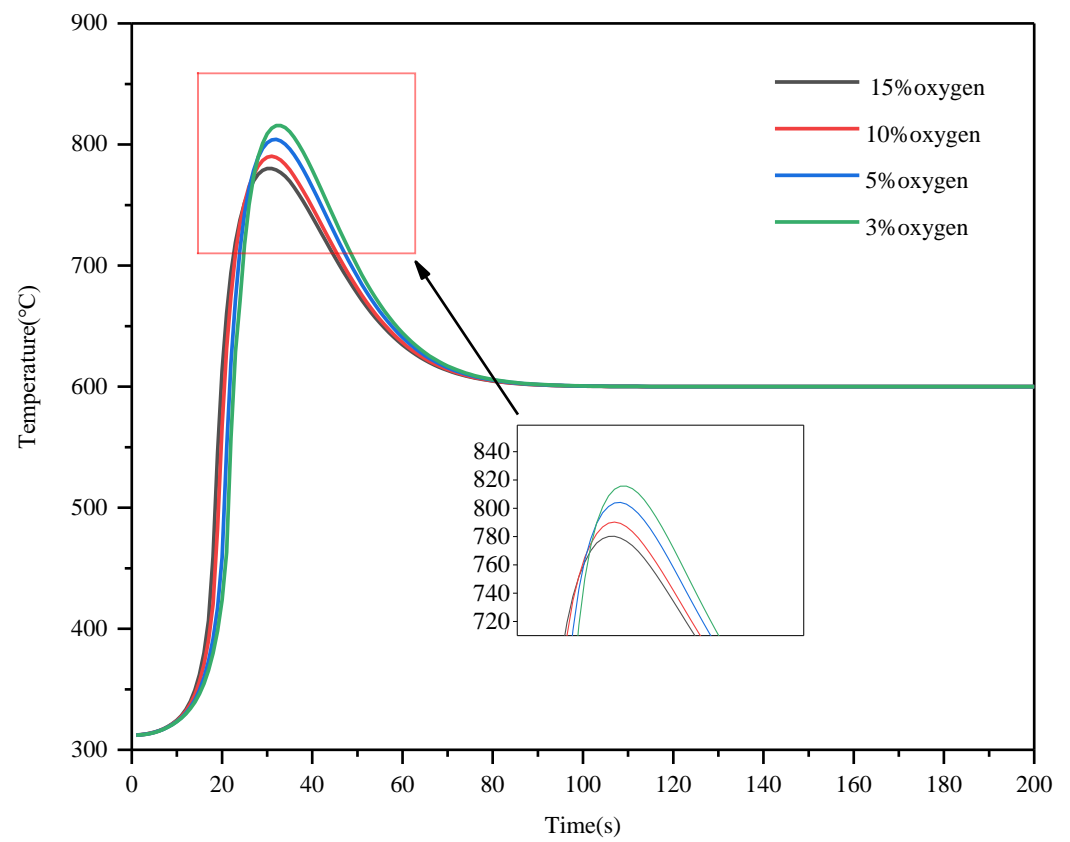

Figure 10. DPF substrate temperature at axial position 0.9 under different oxygen concentrations.

Besides oxygen concentration in exhaust, emission of reactants is another important influencing factor. On one hand, the unburned diesel fuel and carbon monoxide will react in DOC and further increase DOC-out temperature. On the other hand, the nitrogen oxide in exhaust gas will be converted into nitrogen dioxide, which is a strong oxidizing agent of soot in DPF. Thus, regeneration will be influenced by emission of reactants in exhaust. Next, an operating point of $2000 \mathrm{r} / \mathrm{min}$ and $50 \mathrm{~kW}$ output power is selected to investigate the effects of reactants emission on the DOC-DPF system. Table 5 below shows the detailed emission of reactants under this operating point.

Table 5. Emissions under $2000 \mathrm{r} / \mathrm{min}$ and $50 \mathrm{~kW}$ output power.

\begin{tabular}{cc}
\hline Emissions & Mole Fraction \\
\hline Nitrogen & 0.77 \\
Oxygen & 0.13 \\
Carbon dioxide & 0.05 \\
Carbon monoxide & $5 \times 10^{-4}$ \\
Hydrogen & $1.67 \times 10^{-4}$ \\
Water vapor & 0.05 \\
Nitrogen monoxide & $3 \times 10^{-4}$ \\
Nitrogen dixoide & $3.3 \times 10^{-5}$ \\
Unburned diesel vapor & $2 \times 10^{-4}$ \\
\hline
\end{tabular}

The emission data in Table 5 cover all emissions from the tested engine under $2000 \mathrm{r} / \mathrm{min}, 50 \mathrm{~kW}$ output power. The proportion of $\mathrm{NO}_{2}$ and $\mathrm{NO}$ is assumed to be 1:9. The unburned diesel vapor in exhaust is assumed to be composed of propylene and hydrocarbon. The mass flow rate of exhaust is $286.91 \mathrm{~kg} / \mathrm{h}$ and the exhaust temperature is $380{ }^{\circ} \mathrm{C}$. The soot loading and DOC-out temperature is kept at $6 \mathrm{~g} / \mathrm{L}$ and $600{ }^{\circ} \mathrm{C}$, respectively. The injection rate of propylene is $1.61 \mathrm{~kg} / \mathrm{h}$ according to previous results and the initial temperature of DOC is $26.85^{\circ} \mathrm{C}$.

Figure 11 depicts the mass percentages of unburned reactants at the outlet of the DOC along with time. There is no chemical reaction in the first five seconds due to low temperature but adsorption exists in DOC channel. The black solid line indicates the unburned mass fraction of injected propylene and diesel vapor in exhaust. At the very beginning, 33\% injection and diesel vapor are left at the DOC outlet due to the fact that the 
DOC is heated from room temperature. With the increase in temperature, the conversion rate of injected fuels increases rapidly, to higher than $95 \%$ in $20 \mathrm{~s}$. It can be concluded that in real application, when the temperature of DOC substrate is always high, the conversion rate of injected fuel is very high and the reaction happens almost instantaneously in some front part of the DOC channel. The same characteristic applies to carbon monoxide and hydrogen. The mass fraction of carbon monoxide at the DOC outlet decreases from $7 \%$ to $0 \%$ very quickly and there is almost no hydrocarbon left during the whole process, which reveals that hydrocarbon is more active than carbon monoxide in DOC. The above phenomenon verifies that DOC is a device which enables extremely sufficient heat transfer and chemical reactions. The profile of nitrogen monoxide is different. It increases firstly due to the desorption effect of the DOC substrate and then decreases dramatically as the temperature rises. The dashed line in Figure 11 indicates that $5.88 \%$ of nitrogen monoxide is left in the end. It can be concluded that the oxidation of nitrogen monoxide happens along the whole length of the DOC channel. An interesting phenomenon observed from Figure 11 is that nitrogen monoxide is the least active reactant inside DOC. Nitrogen dioxide is a very important oxidizer of carbon in DPF, which is not shown here. However, it demonstrates an opposite trend with nitrogen monoxide, because the whole amount of nitrogen monoxide at the DOC inlet is constant.

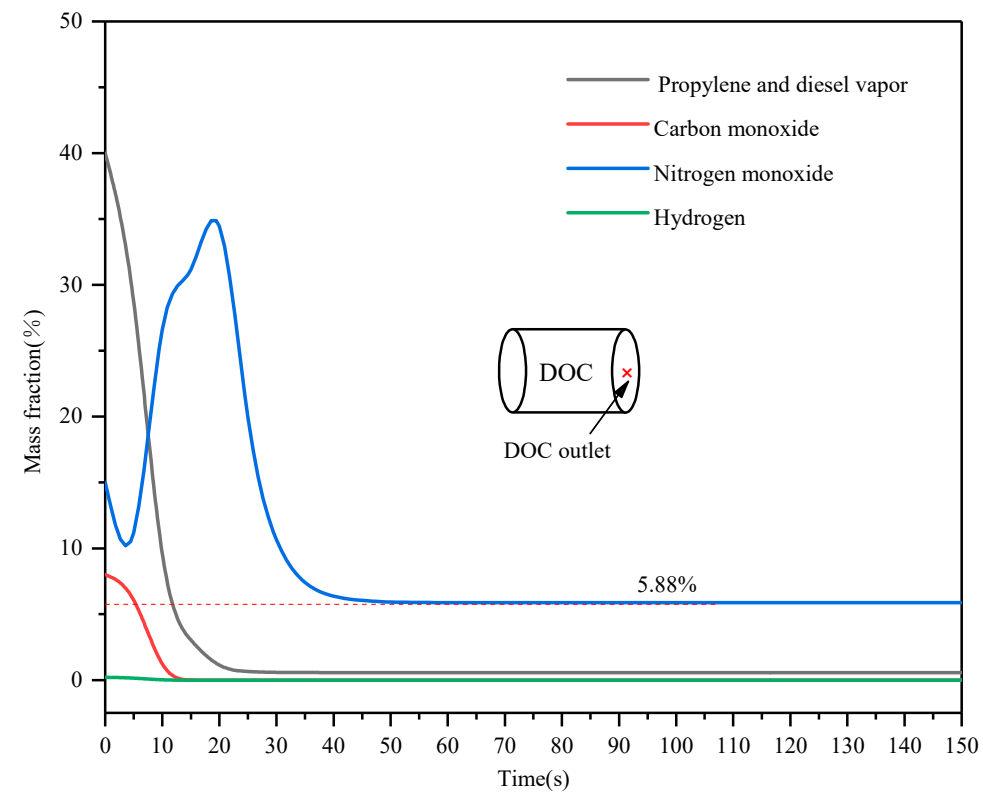

Figure 11. Mass fraction of the main reactants at DOC outlet.

In Figure 12, the outlet temperature of DOC is depicted along with time, with control target equal to $600^{\circ} \mathrm{C}$. The solid line represents the temperature profile with all emissions and the dash-dotted line represents the temperature profile without emissions. The injection rate of propylene is $1.61 \mathrm{~kg} / \mathrm{h}$. As can be observed in Figure 12, the outlet temperature of the DOC rises faster and has a higher steady state temperature with emissions considered. This is due to the exothermic reactions of carbon monoxide, hydrogen, nitrogen monoxide and unburned diesel fuel in exhaust. The specific temperature rise is $41.1^{\circ} \mathrm{C}$, as the dashed lines indicate. It can be speculated that when the emissions are heavier, this temperature rise will be higher and vice versa. The dashed line in the lower part of Figure 12 shows that the outlet temperature of the DOC is lower than the exhaust temperature, which is $380^{\circ} \mathrm{C}$ in the earlier stage. This is because the DOC is a system with large heat capacity and the initial temperature of the DOC is at room temperature. Consequently, a portion of enthalpy is used to heat up the substrate of the DOC, which causes the temperature to become lower than the exhaust temperature during the preliminary stage. 


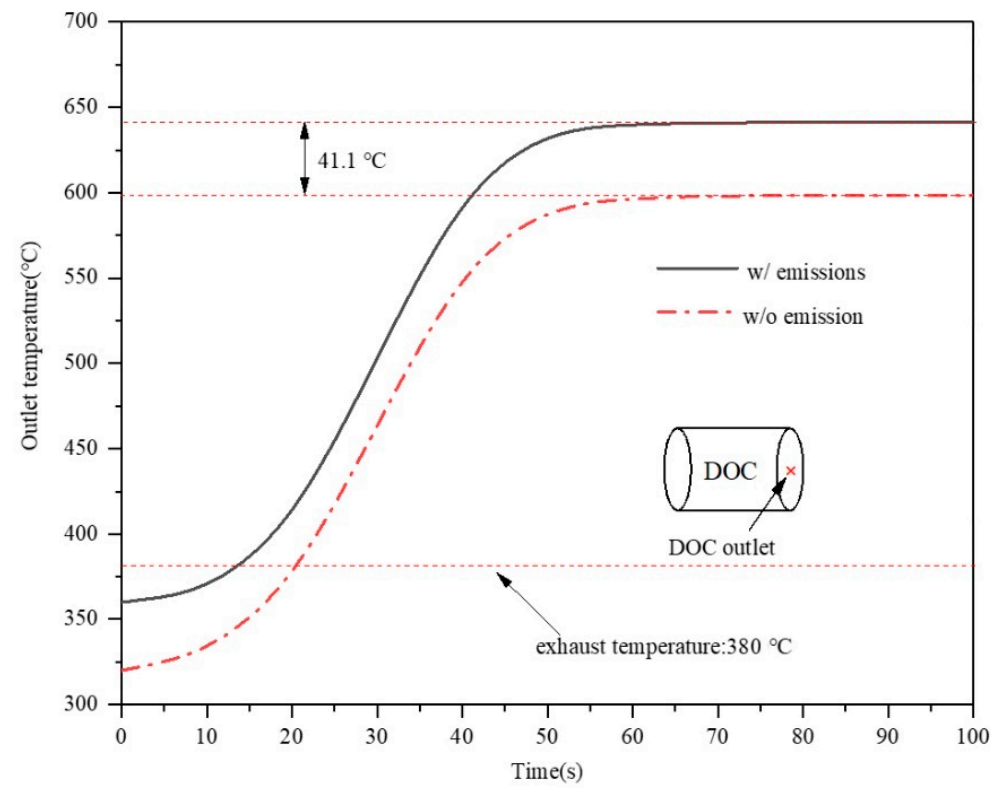

Figure 12. Outlet temperature of DOC with and without emission.

Through previous analysis, we know that propylene, diesel fuel vapor, carbon monoxide and hydrogen are burned rapidly with a very high conversion rate. Nitrogen monoxide is oxidized into nitrogen dioxide with a conversion rate of $94.12 \%$. In addition to the effect of rising DOC-out temperature, the generated nitrogen dioxide will have an effect on soot oxidation in the DPF, for nitrogen dioxide is a strong oxidizing agent of soot. In Figure 13, the influence of nitrogen dioxide on DPF regeneration is depicted.

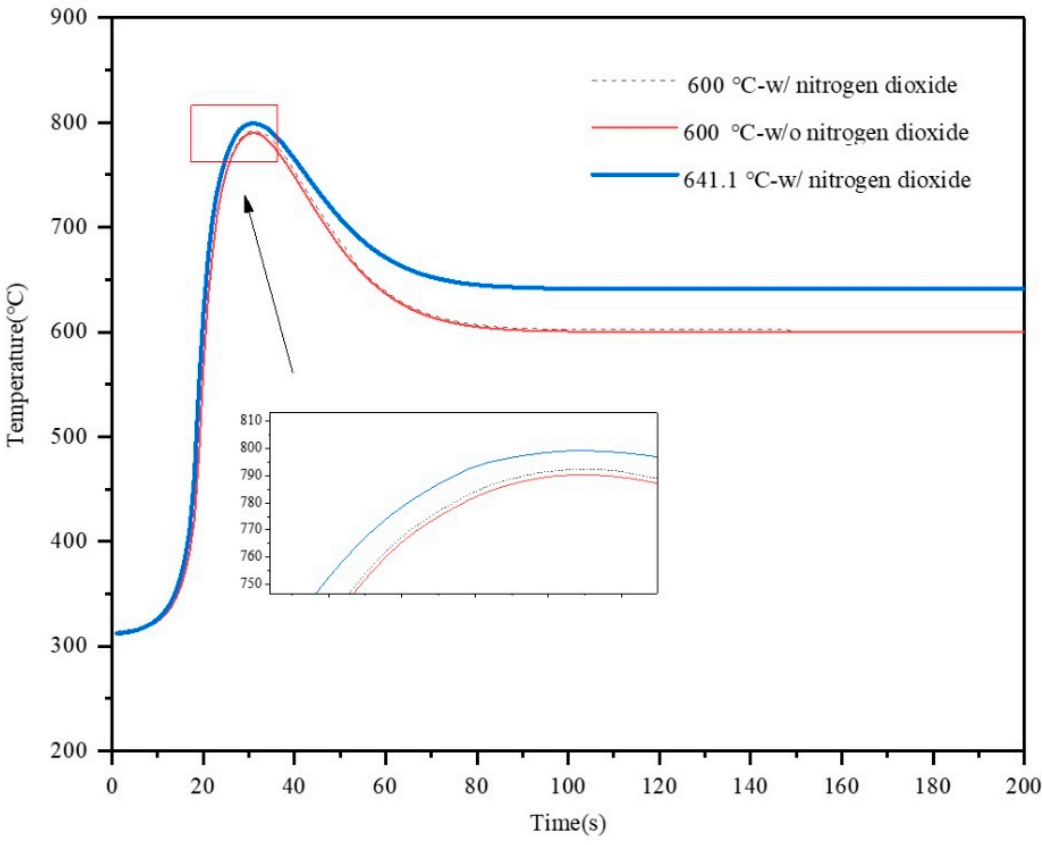

Figure 13. Substrate temperature of DPF at 0.9 normalized axial position considering the soot oxidation by nitrogen dioxide.

The concentration of nitrogen dioxide at the inlet of the DPF is composed of two parts. One is the pre-existing nitrogen dioxide in exhaust and the other is converted from nitrogen monoxide. The specific concentration of nitrogen dioxide at the DPF inlet is computed as $3.2 \times 10^{-4}$. It can be observed from Figure 13 that the dashed line and red line almost overlap, which indicates that the influence of nitrogen dioxide can be neglected. This is 
due to the fact that the oxidation of soot by nitrogen dioxide is greatly inhibited under a high temperature, which is $600^{\circ} \mathrm{C}$ in this case. Another reason is that since there is no catalytic coating or fuel additive in DPF substrate, the continuous regeneration supported by nitrogen dioxide is difficult to proceed. The blue line shows the temperature profile during DPF regeneration, considering the exothermic effect of emissions with nitrogen dioxide. It indicates that the temperature profile is altered merely due to the increase in DPF inlet temperature.

Through the above analysis, it reveals that emissions in exhaust can react in the DOC and raise the outlet temperature of the DOC. The reaction speed is almost instantaneous with a very high conversion rate, except for nitrogen monoxide. The oxidation of soot by nitrogen dioxide is greatly inhibited under the temperature range of active regeneration without catalytic support, which makes the effect of nitrogen dioxide during active regeneration negligible [47]. In general, the gross effect of emissions is equivalent to raising the outlet temperature of the DOC to tens of Celsius.

\subsection{Fuzzy Grey Relational Analysis on the Effects of Significant Factors on DPF Regeneration}

According to previous analysis, the mass flow rate of exhaust, oxygen concentration, soot loading, DOC-out temperature and reactants of emission will influence key indexes concerned during regeneration. However, the effect of reactants in exhaust is equivalent to DOC-out temperature. Therefore, the first four factors are considered and grey relational analysis (GRA) is utilized to quantify the effects of each factor on key indexes in the process of DPF regeneration. By this means, the inherent relationships between influencing factors and regeneration can be revealed, which enables simplification of control strategy designing. The detailed procedures of GRA are as follows:

(1) Establish comparison matrix $X^{\prime}$ and reference matrix $Y$ :

$$
X^{\prime}=\left[\begin{array}{c}
x_{1}^{\prime} \\
x_{2}^{\prime} \\
\vdots \\
x_{m}^{\prime}
\end{array}\right]=\left[\begin{array}{cccc}
x_{1}^{\prime}(1) & x_{1}^{\prime}(2) & \cdots & x_{1}^{\prime}(n) \\
x_{2}^{\prime}(1) & x_{2}^{\prime}(2) & \cdots & x_{2}^{\prime}(n) \\
\vdots & \vdots & \vdots & \vdots \\
x_{m}^{\prime}(1) & x_{m}^{\prime}(2) & \cdots & x_{m}^{\prime}(n)
\end{array}\right]
$$

where $m$ represents the subscript of the influencing factor and equals four in this paper. $n$ represents the number of trials with different factor vectors. The reference matrix $Y$ is as follows:

$$
Y=\left[\begin{array}{cccc}
y_{1}(1) & y_{1}(2) & \cdots & y_{1}(n) \\
y_{2}(1) & y_{2}(2) & \cdots & y_{2}(n) \\
\vdots & \vdots & \vdots & \vdots \\
y_{p}(1) & y_{p}(2) & \cdots & y_{p}(n)
\end{array}\right]
$$

where $p$ represents the subscript of key indexes. In this paper, maximum temperature, maximum rate of temperature increase and regeneration duration are key indexes. Consequently, $p$ is equal to three.

(2) Normalization of comparison matrix by:

$$
x_{i}(k)=\frac{x_{i}^{\prime}(k)-\min x_{i}^{\prime}}{\max x_{i}^{\prime}-\min x_{i}^{\prime}}
$$

where $i$ varies from 1 to $m$ and the normalized form of the comparison matrix is:

$$
X=\left[\begin{array}{c}
x_{1} \\
x_{2} \\
\vdots \\
x_{m}
\end{array}\right]=\left[\begin{array}{cccc}
x_{1}(1) & x_{1}(2) & \cdots & x_{1}(n) \\
x_{2}(1) & x_{2}(2) & \cdots & x_{2}(n) \\
\vdots & \vdots & \vdots & \vdots \\
x_{m}(1) & x_{m}(2) & \cdots & x_{m}(n)
\end{array}\right]
$$


(3) Compute cosine value of fuzzy factors which reflects the similarity of two factors:

$$
r_{1 \_i j}=\frac{\sum_{k=1}^{n} y_{j}(k) x_{i}(k)}{\sqrt{\sum_{k=1}^{n} y_{j}(k)^{2}} \sqrt{\sum_{k=1}^{n} x_{i}(k)^{2}}}
$$

where $i$ ranges from 1 to $m$ and $j$ ranges from 1 to $p$.

(4) Calculate correlation coefficient:

$$
\zeta_{i j}(k)=\frac{\Delta_{\min i j}+l \Delta_{\max i j}}{\Delta(k)+l \Delta_{\max i j}}
$$

where $l$ is the resolution ratio, which is normally 0.5. $\Delta_{\min i j}, \Delta_{\max i j}$ and $\Delta(k)$ can be computed as follows:

$$
\begin{gathered}
\Delta_{\min i j}=\min \left|y_{j}(k)-x_{i}(k)\right| \\
\Delta_{\max i j}=\max \left|y_{j}(k)-x_{i}(k)\right| \\
\Delta(k)=\left|y_{j}(k)-x_{i}(k)\right|
\end{gathered}
$$

(5) Define the weighing coefficient vector, which applies fuzzy Euclidean mathematics for the accuracy of computation, and compute the Euclidean coefficient:

$$
\begin{gathered}
w=\left(w_{1}, w_{2}, \ldots w_{m}\right) \\
r_{2 \_i j}=1-2 \sqrt{\sum_{k=1}^{n}\left[w_{i}\left(1-\zeta_{i j}(k)\right)\right]^{2}}
\end{gathered}
$$

(6) Ultimately, the fuzzy grey correlation coefficient can be calculated as follows:

\begin{tabular}{|c|c|c|c|c|c|c|c|}
\hline Trial & $m(\mathrm{~kg} / \mathrm{h})$ & $T_{\text {set }}\left({ }^{\circ} \mathrm{C}\right)$ & $m_{\text {soot }}(\mathrm{g} / \mathrm{L})$ & $C_{\text {oxygen }}$ & $T_{\max }\left({ }^{\circ} \mathrm{C}\right)$ & $\dot{T}_{\max }\left({ }^{\circ} \mathrm{C} / \mathrm{s}\right)$ & $t_{r e g}(\mathrm{~s})$ \\
\hline 1 & 155.1 & 550 & 3 & 0.05 & 625.6 & 40.8 & 76 \\
\hline 2 & 155.1 & 600 & 6 & 0.1 & 814.8 & 89.8 & 50 \\
\hline 3 & 155.1 & 650 & 9 & 0.15 & 967.2 & 118.9 & 44 \\
\hline 4 & 286.91 & 550 & 6 & 0.15 & 769.5 & 85.1 & 38 \\
\hline 5 & 286.91 & 600 & 9 & 0.05 & 942.1 & 121.6 & 45 \\
\hline 6 & 286.91 & 650 & 3 & 0.1 & 661.1 & 51.6 & 35 \\
\hline 7 & 428.8 & 550 & 9 & 0.1 & 874.6 & 110.2 & 36 \\
\hline 8 & 428.8 & 600 & 3 & 0.15 & 631.7 & 48.4 & 29 \\
\hline 9 & 428.8 & 650 & 6 & 0.05 & 798.1 & 94.7 & 33 \\
\hline
\end{tabular}

$$
r i j=\sqrt{\frac{r_{1}^{2} i j+r_{2}^{2} i j}{2}}
$$

In order to cover more information and simplify the process of analysis, a method of orthogonal design is utilized to establish a comparison and reference matrix. The detailed orthogonal design of trials and computation results is depicted in Table 6.

Table 6. Trials and computation results based on orthogonal design. 
With the data in Table 6, the comparison matrix and reference matrix can be derived as follows:

$$
\begin{aligned}
& X^{\prime}=\left[\begin{array}{ccccccccc}
155.1 & 155.1 & 155.1 & 286.91 & 286.91 & 286.91 & 428.8 & 428.8 & 428.8 \\
550 & 600 & 650 & 550 & 600 & 650 & 550 & 600 & 650 \\
3 & 6 & 9 & 6 & 9 & 3 & 9 & 3 & 6 \\
0.05 & 0.1 & 0.15 & 0.15 & 0.05 & 0.1 & 0.1 & 0.15 & 0.05
\end{array}\right] \\
& Y=\left[\begin{array}{ccccccccc}
625.6 & 814.8 & 967.2 & 769.5 & 942.1 & 661.1 & 874.6 & 631.7 & 798.1 \\
40.8 & 89.8 & 118.9 & 85.1 & 121.6 & 51.6 & 110.2 & 48.4 & 94.7 \\
76 & 50 & 44 & 38 & 45 & 35 & 36 & 29 & 33
\end{array}\right]
\end{aligned}
$$

Figure 14 depicts the fuzzy grey correlation coefficient of exhaust flow rate, DOCout temperature, soot loading and oxygen concentration on key indexes during DPF regeneration. The horizontal axis represents the maximum temperature $\left(\mathrm{y}_{1}\right)$, maximum rate of temperature increase $\left(\mathrm{y}_{2}\right)$ and regeneration duration $\left(\mathrm{y}_{3}\right)$, respectively. Based on specific values of fuzzy grey correlation coefficients in Figure 14, soot loading is the most related factor to maximum temperature during regeneration. DOC-out temperature takes the second place. Exhaust flow rate and oxygen concentration have approximately the same effects on maximum temperature. Regarding the maximum rate of temperature increase, soot loading is in a dominant position and the other three factors take roughly equal effects. Soot loading again is the most related factor to regeneration duration, whose fuzzy grey rational coefficient is 0.59 . DOC-out temperature is the second most related factor to regeneration duration. Exhaust flow rate has the minimum effect on regeneration duration. In general, soot loading is the most significant factor influencing DPF regeneration. Therefore, it is crucial to evaluate soot deposited in real application. DOC-out temperature has a relatively smaller effect than soot loading but should be controlled accurately to guarantee safe regeneration. The other two factors have less influence on regeneration. Consequently, exhaust flow rate and oxygen concentration can be put in secondary positions when simplified analysis is needed. However, it is worth noting that the emission of reactants in exhaust is significant due to its equivalent effect to DOC-out temperature.

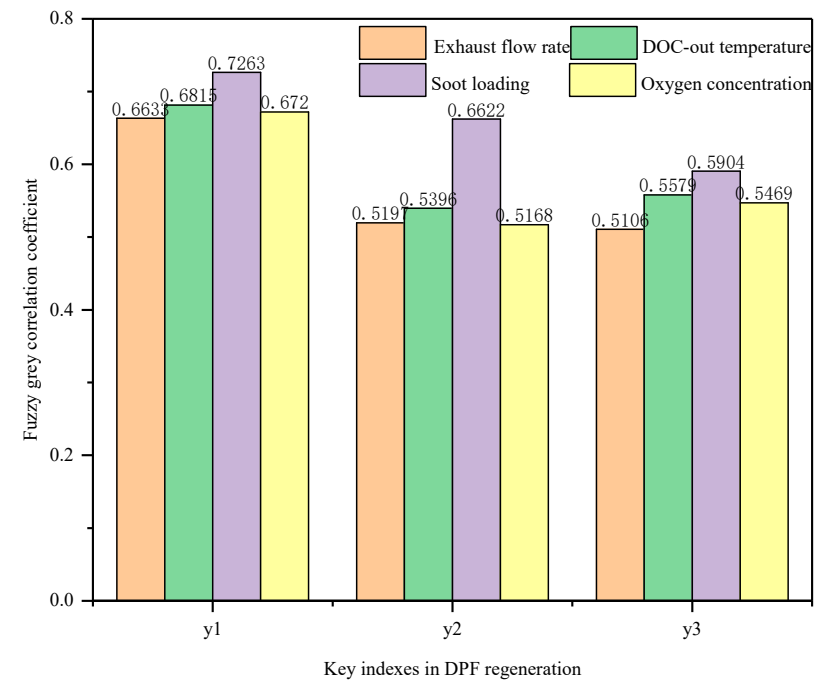

Figure 14. Fuzzy grey relational analysis of DPF regeneration.

\section{Conclusions}

(1) The required amount of propylene injection to reach a specific DOC-out temperature can be obtained by the following procedures: the maps of exhaust mass flow rate and temperature are calibrated based on engine speed and output power by experiments; and the map of propylene injection is calculated based on exhaust mass flow rate 
and temperature by energy conservation equation. With engine speed and output power known, the amount of propyleneinjection can be acquired by inquiring the aforementioned maps in sequence.

(2) With the increase in exhaust mass flow rate, the maximum temperature of DPF substrate during regeneration decreases due to enhanced convection between exhaust gas and substrate. When the engine speed is as low as the idle speed, an auxiliary air device is needed to supply enough oxygen.

(3) The maximum temperature and maximum rate of temperature increase rises monotonously with the rise in soot loading and DOC-out temperature. The influence of soot loading is more obvious. The regeneration duration has little difference except for very low soot loading with relatively low DOC-out temperature, under which regeneration will last for a while. Therefore, it is uneconomic to start regeneration in this scenario.

(4) With the increase in oxygen concentration, the oxidation rate of soot increases. However, the maximum temperature of the DPF substrate decreases with the increasing oxygen concentration. This is due to the decrease in exhaust density, which raises the volume flow rate of exhaust and further enhances convection between exhaust and substrate. In general, oxygen concentration is abundant enough to support soot oxidation under the majority of engine operating points.

(5) All the emissions of reactants react in the DOC almost instantaneously in some front part of the DOC channel with very high conversion rate, except for nitrogen monoxide. Nitrogen dioxide has little impact on soot oxidation mainly due to the fact that the reaction between soot and nitrogen dioxide is greatly inhibited in the temperature range of active regeneration. Therefore, the effect of the emission of reactants is equivalent to raising the DOC-out temperature to dozens of degrees.

(6) Soot loading is the most dominant factor which influences DPF regeneration. Its fuzzy grey correlation coefficient to maximum temperature, maximum rate of temperature increase and regeneration duration are $0.726,0.662$ and 0.59 , respectively. DOC-out temperature takes the second place, whose fuzzy grey correlation coefficient in key indexes is $0.681,0.54$ and 0.558 , respectively. Consequently, it is crucial to evaluate soot deposition inside the DPF accurately and control DOC-out temperature precisely. The other two factors, like exhaust mass flow rate and oxygen concentration, can be omitted for the sake of simplification. It is worth noting that emission of reactants has to be considered in designing a DOC-out temperature controller for its equivalent effect to raising DOC-out temperature by dozens of degrees.

Author Contributions: Conceptualization, G.L. and W.L.; methodology, Y.H. and J.G.; software, Q.L.; validation, W.L. and J.G.; formal analysis, G.L.; Investigation, G.L. and W.L.; resources, G.L., Y.H., J.G. and Q.L.; data curation, W.L.; writing — original draft preparation, G.L. and W.L.; writingreview and editing, J.G.; visualization, Q.L.; supervision, J.G.; project administration, G.L. and Y.H.; funding acquisition, G.L. and Y.H. All authors have read and agreed to the published version of the manuscript.

Funding: This research was funded by Application Technology Special Project of Hunan Industry Polytechnic: Research of Vehicle Particulate Filter Regeneration, grant number GYKYYJ202007 and Natural Science Foundation of Hunan Province, China, grant number 2017JJ5016, 2021JJ60030.

Institutional Review Board Statement: Not applicable.

Informed Consent Statement: Not applicable.

Data Availability Statement: The data presented in this study are available in the main text of the article.

Acknowledgments: This work is supported by the Application Technology Special Project of Hunan Industry Polytechnic: Research of Vehicle Particulate Filter Regeneration (GYKYYJ202007) and the Natural Science Foundation of Hunan province, China (2017JJ5016).

Conflicts of Interest: The authors declare no conflict of interest. 


\section{Nomenclature}

a

$A_{0}$

$C_{p g}$

$\mathrm{C}_{p p}$

$C_{p s}$

coxygen

d

$D_{h}$

$f$

$f_{s b}$

$h$

$h_{1}$

$h_{2}$

$h_{x}$

$k_{i}$

$m$

$m_{\text {soot }}$

$\dot{m}$

$\mathrm{Nu}$

$p$

$P$

$r_{j}$

$r_{i j}$

$r_{1 \_i j}$

$r_{2}$ ij

$S$

$S_{x}$

$t$

$t_{\text {reg }}$

$T_{1}$

$\mathrm{T}_{2}$

$T_{g}$

$T_{S}$

$T_{w}$

$T_{x}$

$T_{\text {exg }}$

$T_{\max }$

$\dot{T}_{\text {max }}$

$T_{\text {set }}$

$v$

$v_{i}$

$v_{w}$

V

$w$

$w_{S}$

$x$

$X^{\prime}$

$X$

Y

$z$

Greek Symbols

$\varepsilon$ square channel pressure drop correlation

frontal area of DOC

heat capacity of exhaust at constant pressure

heat capacity of soot cake

heat capacity of DPF substrate

oxygen concentration in exhaust

diameter of DPF channel

diameter of DOC channel

friction factor between exhaust and DOC substrate

solid fraction of DOC substrate

heat transfer coefficient between exhaust and DOC substrate heat transfer coefficient of inlet exhaust and DPF substrate heat transfer coefficient of outlet exhaust and DPF substrate heat transfer coefficient between DOC and ambient

chemical reaction constants in DOC and DPF

engine exhaust mass flow rate

soot loading in DPF

injecting rate of propylene

Nusselt number for fully developed laminar flow

pressure in DOC channel

external input power into DOC

reaction rate of reactant $j$

fuzzy grey correlation coefficient

cosine value of fuzzy factors

Euclidean coefficient

surface area per DOC volume

heat exchange area between DOC and ambient

time

regeneration duration

inlet gas temperature of DPF

outlet gas temperature of DPF

exhaust temperature in DOC channel

substrate temperature of DOC

temperature of DPF wall

ambient temperature

temperature of engine-out exhaust

maximum temperature of DPF substrate during regeneration

maximum rate of temperature increase

pre-defined DOC outlet temperature

velocity of exhaust in DOC channel

velocity of exhaust in DPF inlet and outlet channel $(i=1, i=2)$

velocity of exhaust in DPF wall

DOC volume

thickness of DPF channel

thickness of sootcake

vertical coordinate of DPF channel

comparison matrix

normalized comparison matrix

reference matrix

axial coordinate of DOC and DPF channel

void fraction of DOC substrate 


$\begin{array}{ll}\phi & \text { chemical reaction enthalpy in DPF wall } \\ \eta & \text { conversion rate of injected propylene } \\ \lambda_{g} & \text { thermal conductivity of exhaust in DOC } \\ \lambda_{p} & \text { thermal conductivity of soot cake } \\ \lambda_{s} & \text { thermal conductivity of DPF substrate } \\ \lambda_{s b} & \text { thermal conductivity of DOC substrate } \\ u & \text { exhaust viscosity } \\ \rho_{g} & \text { exhaust density in DOC channel } \\ \rho_{i} & \text { exhaust density of DPF inlet and outlet channel }(i=1, i=2) \\ \rho_{p} & \text { soot cake density } \\ \rho_{s} & \text { density of DPF substrate } \\ \rho_{w} & \text { exhaust density in DPF wall } \\ \Psi_{S} & \text { effective heat capacity of DOC } \\ S_{i j} & \text { correlation coefficient } \\ \Delta H_{j} & \text { low heating value of reactant } j \text { in DOC } \\ \Delta H & \text { low heating value of injected propylene } \\ \text { Abbreviations } & \\ \text { CRT } & \text { continuous regeneration technology } \\ \text { DOC } & \text { diesel oxidation catalyst } \\ \text { DPF } & \text { diesel particulate filter } \\ \text { ECU } & \text { electric control unit } \\ \text { GRA } & \text { grey relational analysis } \\ \text { HCCI } & \text { homogeneous charge compression ignition } \\ n r c t & \text { number of reactants }\end{array}$

\section{References}

1. Agarwal, A.; Gupta, T.; Shukla, P.C.; Dhar, A. Particulate emissions from biodiesel fuelled CI engines. Energy Convers. Manag. 2015, 94, 311-330. [CrossRef]

2. Zhang, Z.; Balasubramanian, R. Investigation of particulate emission characteristics of a diesel engine fueled with higher alcohols/biodiesel blends. Appl. Energy 2016, 163, 71-80. [CrossRef]

3. Yadav, J.; Ramesh, A. Injection strategies for reducing smoke and improving the performance of a butanol-diesel common rail dual fuel engine. Appl. Energy 2018, 212,1-12. [CrossRef]

4. Li, G.; Zhang, C.; Li, Y. Effects of diesel injection parameters on the rapid combustion and emissions of an HD common-rail diesel engine fueled with diesel-methanol dual-fuel. Appl. Therm. Eng. 2016, 108, 1214-1225. [CrossRef]

5. Bendu, H.; Deepak, B.B.V.L.; Murugan, S. Application of GRNN for the prediction of performance and exhaust emissions in HCCI engine using ethanol. Energy Convers. Manag. 2016, 122, 165-173. [CrossRef]

6. Yousefi, A.; Gharehghani, A.; Birouk, M. Comparison study on combustion characteristics and emissions of a homogeneous charge compression ignition (HCCI) engine with and without pre-combustion chamber. Energy Convers. Manag. 2015, 100, 232-241. [CrossRef]

7. Pacheco, A.F.; Martins, M.E.S.; Zhao, H. New European Drive Cycle (NEDC) simulation of a passenger car with a HCCI engine: Emissions and fuel consumption results. Fuel 2013, 111, 733-739. [CrossRef]

8. Kim, K.; Kim, J.; Oh, S.; Kim, C.; Lee, Y. Lower particulate matter emissions with a stoichiometric LPG direct injection engine. Fuel 2017, 187, 197-210. [CrossRef]

9. Überall, A.; Otte, R.; Eilts, P.; Krahl, J. A literature research about particle emissions from engines with direct gasoline injection and the potential to reduce these emissions. Fuel 2015, 147, 203-207. [CrossRef]

10. Rakopoulos, C.; Dimaratos, A.; Giakoumis, E.; Rakopoulos, D. Evaluation of the effect of engine, load and turbocharger parameters on transient emissions of diesel engine. Energy Convers. Manag. 2009, 50, 2381-2393. [CrossRef]

11. Quan-Shun, Y.; Jian-Wei, T.; Yun-Shan, G.; Li-Jun, H.; Zi-Hang, P. Application of diesel particulate filter on in-use on-road vehicles. Energy Procedia 2017, 105, 1730-1736. [CrossRef]

12. Torregrosa, A.J.; Serrano, J.R.; Piqueras, P.; Óscar, G.-A. Exerimental and computational approach to the transient behavior of wall-flow diesel particulate filters. Energy 2017, 119, 887-900. [CrossRef]

13. Chen, P.; Ibrahim, U.; Wang, J. Experimental investigation of diesel and biodiesel post injections during active diesel particulate filter regenerations. Fuel 2014, 130, 286-295. [CrossRef]

14. Dwyer, H.; Ayala, A.; Zhang, S.; Collins, J.; Huai, T.; Herner, J.; Chau, W. Emissions from a diesel car during regeneration of an active diesel particulate filter. J. Aerosol Sci. 2010, 41, 541-552. [CrossRef]

15. Pérez, V.R.; Bueno-López, A. Catalytic regeneration of diesel particulate filters: Comparison of Pt and CePr active phases. Chem. Eng. J. 2015, 279, 79-85. [CrossRef]

16. Li, H.; Song, C.; Lv, G.; Pang, H.; Qiao, Y. Assessment of the impact of post-injection on exhaust pollutants emitted from a diesel engine fueled with biodiesel. Renew. Energy 2017, 114, 924-933. [CrossRef] 
17. Palma, V.; Meloni, E. Microwave assisted regeneration of a catalytic diesel soot trap. Fuel 2016, 181, 421-429. [CrossRef]

18. Yamamoto, K.; Sakai, T. Simulation of continuously regenerating trap with catalyzed DPF. Catal. Today 2015, 242, 357-362. [CrossRef]

19. Caliskan, H.; Mori, K. Environmental, enviroeconomic and enhanced thermodynamic analysis of a diesel engine with diesel oxidation catalyst(DOC) and diesel particulate filter (DPF) after treatment systems. Energy 2017, 128, 128-144. [CrossRef]

20. Millo, F.; Rafigh, M.; Andreata, M.; Vlachos, T.; Arya, P.; Miceli, P. Impact of high sulfur fuel and de-sulfation process on a close-coupled diesel oxidation catalyst and diesel particulate filter. Fuel 2017, 198, 58-67. [CrossRef]

21. Tsuneyoshi, K.; Yamamoto, K. A study on the cell structure and the performances of wall-flow diesel particulate filter. Energy 2012, 48, 492-499. [CrossRef]

22. Tsuneyoshi, K.; Yamamoto, K. Experimental study of hexagonal and square diesel particulate filters under controlled and uncontrolled catalyzed regeneration. Energy 2013, 60, 325-332. [CrossRef]

23. Deng, Y.; Zheng, W.; E, J.; Zhang, B.; Zhao, X.; Zuo, Q.; Zhang, Z.; Han, D. Influence of geometric characteristics of a diesel particulate filter on its behavior in equilibrium state. Appl. Therm. Eng. 2017, 123, 61-73. [CrossRef]

24. Rodríguez-Fernández, J.; Hernández, J.J.; Sánchez-Valdepeñas, J. Effect of oxygenated and paraffinic alternative diesel fuels on soot reactivity and implications on DPF regeneration. Fuel 2016, 185, 460-467. [CrossRef]

25. Lundberg, B.; Sjöblom, J.; Johansson, Å.; Westerberg, B.; Creaser, D. DOC modeling combining kinetics and mass transfer using inert washcoat layers. Appl. Catal. B Environ. 2016, 191, 116-129. [CrossRef]

26. Sampara, C.S.; Bissett, E.J.; Chmielewski, M. Global kinetics for a commercial diesel oxidation catalyst with two exhaust hydrocarbons. Ind. Eng. Chem. Res. 2008, 47, 311-322. [CrossRef]

27. Wang, T.J.; Baek, S.W.; Lee, J.-H. Kinetic parameter estimation of a diesel oxidation catalyst under actual vehicle operating conditions. Ind. Eng. Chem. Res. 2008, 47, 2528-2537. [CrossRef]

28. Depcik, C.; Assanis, D. One-dimensional automotive catalyst modeling. Prog. Energy Combust. Sci. 2005, 31, 308-369. [CrossRef]

29. Schejbal, M.; Marek, M.; Kubíček, M.; Kočí, P. Modelling of diesel filters for particulates removal. Chem. Eng. J. 2000, 154, 219-230. [CrossRef]

30. Schejbal, M.; Štčpánek, J.; Marek, M.; Kočí, P.; Kubíček, M. Modelling of soot oxidation by $\mathrm{NO}_{2}$ in various types of diesel particulate filters. Fuel 2010, 89, 2365-2375. [CrossRef]

31. Cozzolini, A. Advanced DOC-DPF Model to Predict Soot Accumulation and Pressure Drop in Diesel Particulate Filters. Ph.D. Thesis, West Virginia University, Morgantown, WV, USA, 2019.

32. Morcos, M.; Ayyappan, P.; Harris, T. Charaterization of DPF for development of DPF regeneration control and ash cleaning requirements. SAE Tech. Paper 2011, 1, 1248.

33. Beatrice, C.; Di Iorio, S.; Guido, C.; Napolitano, P. Detailed characterization of particulate emissions of an automotive catalyzed DPF using actual regeneration strategies. Exp. Therm. Fluid Sci. 2012, 39, 45-53. [CrossRef]

34. Tadrous, T.N.; Brown, K. Development of passive/active DPF system utilizing syngas regeneration strategy-retrofit, real life optimization and performance experience. SAE Tech. Paper 2010, 1, 560.

35. Dawei, Q.; Jun, L.; Yu, L. Research on particulate filter simulation and regeneration control strategy. Mech. Syst. Signal Process. 2017, 87, 214-226. [CrossRef]

36. Bai, S.; Chen, G.; Sun, Q.; Wang, G.; Li, G. Influence of active control strategies on exhaust thermal management for diesel particular filter active regeneration. Appl. Therm. Eng. 2017, 119, 297-303. [CrossRef]

37. Singh, N.; Rutland, C.J.; Foster, D.E.; Narayanaswamy, K.; He, Y. Investigation into different DPF regeneration strategies based on fuel economy using integrated system simulation. SAE Tech. Paper 2009, 1, 1275. [CrossRef]

38. Gong, J.; Rutland, C.J. Pulsed regeneration for DPF aftertreatment devices. SAE Tech. Paper 2011, 24, 182. [CrossRef]

39. Bai, S.; Tang, J.; Wang, G.; Li, G. Soot loading estimation model and passive regeneration characteristics of DPF system for heavy-duty engine. Appl. Therm. Eng. 2016, 100, 1292-1298. [CrossRef]

40. Ning, J.; Yan, F. Composite control of DOC-out temperature for DPF regeneration. IFAC PapersOnLine 2016, 49, 20-27. [CrossRef]

41. Kim, Y.-W.; Van Nieuwstadt, M.; Stewart, G.; Pekar, J. Model predictive control of DOC temperature during DPF regeneration. SAE Tech. Paper 2014, 1, 1165. [CrossRef]

42. Lepreux, O.; Creff, Y.; Petit, N. Model-based temperature control of a diesel oxidation catalyst. J. Process. Control. 2012, 22, 41-50. [CrossRef]

43. Lepreux, O.; Creff, Y.; Petit, N. Motion planning for a diesel oxidation catalyst outlet temperature. In Proceedings of the American Control Conference, Seattle, WA, USA, 11-13 June 2008.

44. Bissett, E.J. Mathematical model of the thermal regeneration of a wall-flow monolith diesel particulate filter. Chem. Eng. Sci. 1984, 39, 1233-1244. [CrossRef]

45. AVL. Boot Theory Guide; AVL Inc.: Graz, Austria, 2018.

46. Yamamoto, K.; Oohori, S.; Yamashita, H.; Daido, S. Simulation on soot deposition and combustion in diesel particulate filter. Proc. Combust. Inst. 2009, 32, 1965-1972. [CrossRef]

47. Tighe, C.J.; Twigg, M.V.; Hayhurst, A.; Dennis, J. The kinetics of oxidation of diesel soots by $\mathrm{NO}_{2}$. Combust. Flame 2012, 159, 77-90. [CrossRef] 